\title{
Polymorphism of CYP2C19 gene polymorphism in Patients with Coronary Heart Disease in Chongqing
}

\author{
Yishu Tang*, Yang Yang, Ru Wu, Miao Gao, Fang Cui
}

Department of Laboratory Medicine, The First Affiliated Hospital of Chongqing Medical University, Chongqing, People’s Republic of China

*Corresponding Author: Yishu Tang, Department of Laboratory Medicine, The First Affiliated Hospital of Chongqing Medical University, No. 1 Youyi Road, Yuzhong District, Chongqing, 400016, China, E-mail: 916403117@qq.com

Received: 14 March 2018; Accepted: 18 April 2018; Published: 20 April 2018

\begin{abstract}
Objective: To explore the distribution of drug metabolic enzymes CYP2C19 genetic polymorphism in coronary heart disease (CAD) patients of Chongqing.
\end{abstract}

Methods: We have done genotyping to 179 CAD patients taking clopidogrel by gene chip method, analyzed the distribution of genotype and metabotropic phenotype.

Results: In this study, a total of six different CYP2C19 genotypes and three metabotropic phenotypes were detected. The frequency of the homozygous extensive metabolizer phenotype was 32.96\% (59/179), the heterozygous extensive metabolizer phenotype was 53.07\% (95/179) and the poor metabolizers was 13.96\% (25/179). Among the CAD patients in Chongqing, there is no significant statistical difference between these CYP2C19 genotypes and reports in other studies

Conclusion: The CYP2C9 gene existed genetic polymorphism in CAD patients in Chongqing, and the distributions of allele frequency and metabolic phenotype frequency are similar to other districts in China.

Keywords: Coronary heart disease; CYP2C19; Gene polymorphism; Metabolic phenotype; Clopidogrel 


\section{Introduction}

The use of clopidogrel in combination with aspirin is recommended for the prevention of coronary heart disease (CAD) according to current guidelines [1]. Despite of the standard treatment, the antiplatelet effect of clopidogrel was obviously different between individuals. About 4\%-30\% patient taken conventional dose clopidogrel have no antiplatelet effect [2]. There are still numerous adverse cardiovascular events, and clopidogrel resistance (CR) is regarded to be the main reasons.

CYP2C19 enzyme was an important part in the cytochrome P450 drug metabolizing enzyme family, which could turn the clopidogrel precursor into active metabolite to inhibit platelet aggregation. A variety of factors, including external and internal factors, have influenced the mechanism of CR. The CYP2C19 gene polymorphisms was a key factor in clopidogrel oxidative metabolism. The main mutant alleles, CYP2C19*2 and CYP2C19*3, are the most common genotypes in Asian populations (frequency of 30\%-50\% and 5\%-10\%, respectively) [3]. The presence of CYP2C19*2 or CYP2C19*3 mutant allele increases CR risk [4].

Therefore, this study aimed to investigate CYP2C19 polymorphisms in clopidogrel-treated CAD patients in Chongqing. Then we could provide the early prediction of CAD, and guide drug usage to reduce the ratio of adverse cardiovascular events.

\section{Materials and Methods}

\subsection{Study populations}

The patients were selected from May 2015 to October 2017. A total of 179 clopidogrel on-treatment CAD patients were enrolled in the study, including123 male and 66 female. This study was approved by the Institutional Review Board (IRB) committee of The First Affiliated Hospital of Chongqing Medical University. Written consent given by the patients was waived by the approving IRB.

\subsection{CYP2C19 gene polymorphism analysis}

Anticoagulation with EDTA was applied in vitro to detect CYP2C19 gene polymorphism. The nucleic acid was extracted from anticoagulation blood and PCR amplification. Once combined with a hybridization buffer (Baio Corporation), the products were placed in a chip hybridization instrument (Baio Corporation) for hybridization. Finally, the chip was placed in chip identification system for scanning and interpretation (Baio Corporation)

\subsection{Statistical analysis}

Statistical analyses were performed using the SPSS software, version 19.0 (SPSS, IL, USA). Allele frequencies were analyzed using $\mathrm{X} 2$ test. $\mathrm{P}<0.05$ was considered statistically significant.

\section{Results}

The Table 1 and Figure 1 demonstrated that there were 6 genotypes and 3 metabolic types about CYP2C19 gene polymorphism. The six genotypes have included the CYP2C19*1/*1, *1/*2, *1/*3, *2/*2, *2/*3 and *3/*3. The three metabolic types have included Extensive Metabolizer (EM), Intermediate Metabolizer (IM), Poor Metabolizer 
(PM). The CYP2C19*1/*1 belonged to EM, CYP2C19*1/*2 and *1/*3 belonged to IM, and CYP2C19*2/*2,*2/*3 and $* 3 / * 3$ belonged to $\mathrm{PM}$.

\begin{tabular}{|c|c|c|}
\hline Genotype & Polymorphic site & Metabolic type \\
\hline CYP2C19* 1/*1 & 636GG, 68lGG & EM \\
\hline CYP2C19* 1/*2 & 636GG, 68lGA & IM \\
\hline CYP2C19* 1/*3 & 636GA, 68lGG & IM \\
\hline CYP2C19*2/*2 & 636GG, 68lAA & PM \\
\hline CYP2C19*3/*3 & 636AA, 68lGG & PM \\
\hline CYP2C19* 2/*3 & 636GA, 68lGA & PM \\
\hline
\end{tabular}

Table 1: The genotype and metabolic type of CYP2C19
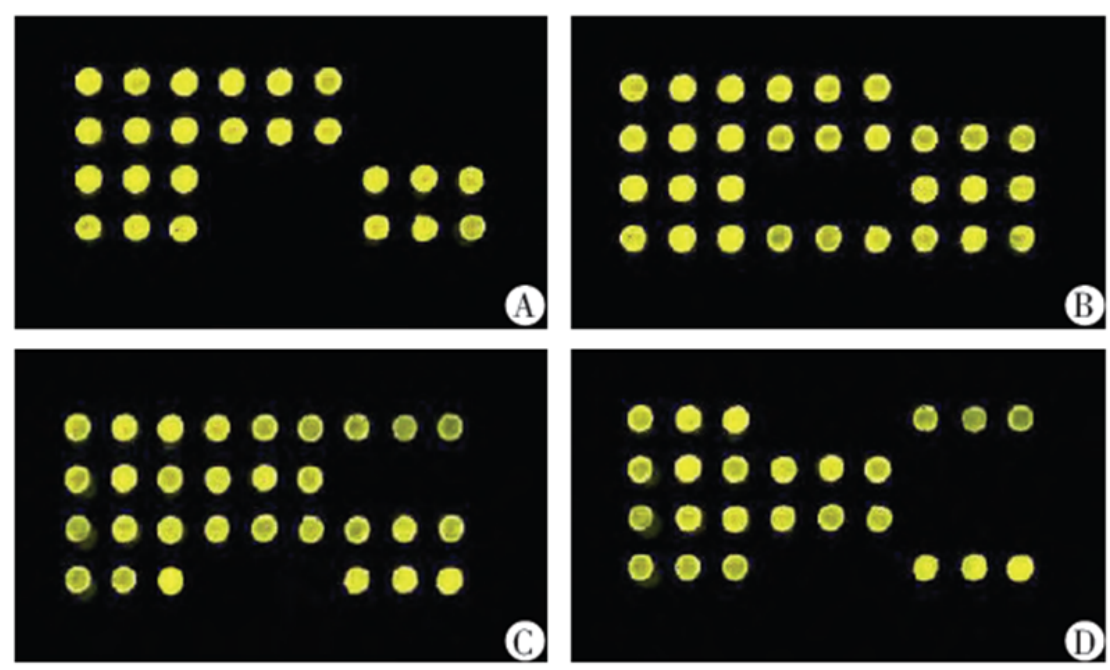

-

00000000

- 00000000

00000000

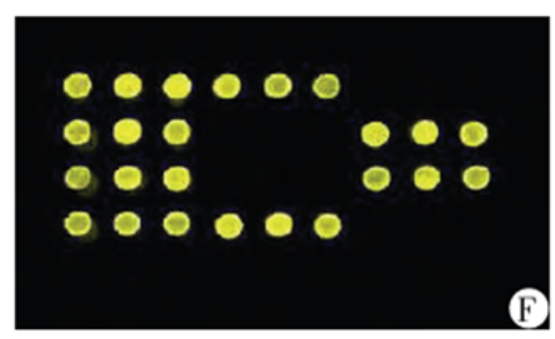

Figure 1: The mode pattern of CYP2C19 gene chip $\mathrm{A} * 1 / * 1 ; \mathrm{B} * 1 / * 2 ; \mathrm{C} * 1 / * 3 ; \mathrm{D} * 2 / * 2 ; \mathrm{E}^{*} 2 / * 3 ; \mathrm{F} * 3 / * 3$

The Table 2 and Table 3 demonstrated that 59 patients were EM (32.96\%), 95 patients were IM (53.07\%), and 25 patients were PM (13.96\%).We detected 49 patients without mutation on the 681 site and 636 site. But there were 130 patients mutated on 681 site $\mathrm{G}>\mathrm{A}$ or (and) 636 site $\mathrm{G}>\mathrm{A}$. 


\begin{tabular}{|c|c|c|}
\hline Genotype & Metabolic type & Ratio N(\%) \\
\hline CYP2C19* 1/*1 & EM & $59(32.96)$ \\
\hline CYP2C19* 1/*2 & IM & $76(42.46)$ \\
\hline CYP2C19*1/*3 & IM & $19(10.61)$ \\
\hline CYP2C19* 2/*2 & PM & $18(10.05)$ \\
\hline CYP2C19*3/*3 & PM & $1(0.05)$ \\
\hline CYP2C19* 2/*3 & PM & $6(3.35)$ \\
\hline
\end{tabular}

Table 2: The distribution of CYP2C19 genotype

Compared to the distribution of metabolic type in other districts, the ratio of Chongqing had no statistical difference ( $\mathrm{P}>0.05$, Table 3$)$.

\begin{tabular}{|l|l|l|l|l|l|}
\hline Group & $\mathrm{n}$ & EM & IM & PM & P \\
\hline Chongqing(CAD) & 179 & $59(32.96)$ & $95(53.07)$ & $25(13.96)$ & \\
\hline Wuhan (CAD) & 123 & $38(30.9)$ & $69(56.1)$ & $16(13.0)$ & 0.125 \\
\hline Beijing(Health people) & 283 & $120(42.4)$ & $123(43.5)$ & $40(14.1)$ & 0.065 \\
\hline Henan(Health people) & 161 & $65(40.4)$ & $68(42.2)$ & $28(17.4)$ & 0.071 \\
\hline
\end{tabular}

Table 3: The distribution of metabolic type of CYP2C19 [N (\%)]

\section{Discussion}

Clopidogrel is an oral prodrug which needs to be converted to an active metabolite. CYP2C19 enzyme hydrolyzed 85\% of clopidogrel to inactive metabolites. CYP2C19 genotype affected metabolic steps and was the most important part of the pharmacokinetic and pharmacodynamic responses to clopidogrel [5, 6].

The presence of any dysfunctional CYP2C19 alleles $(* 2, * 3, * 4, * 5)$ is associated with CR risk $[7,8]$. Gene mutations regulated clopidogrel absorption and excretion.

In the present study, we observed that the frequencies of CYP2C19*2 and CYP2C19*3 alleles in the experimental group and the control group were consistent with those reported by Zou et al. [9], and were higher than those reported in Swedish Caucasians [10] and Ethiopians [11], confirming that allelic variants exhibit ethnic and geographic diversity. The previous studies showed that CYP2C19*2 or *3 mutant allele had effected platelet function and resulted in more poor platelet inhibition rates than wild-type. The carriers of CYP2C19*2 or *3 mutant allele demonstrated poor response to clopidogrel therapy and increased rates of CR [8].

The patients with CAD were received both clopidogrel and aspirin treatment. But the carrier with CYP2C19*2 or *3 mutant allele connected to a higher risk of CR, leading to increased incidence of adverse cardiovascular events. The pharmacogenomic testing of CYP2C19 is recommended by the American College of Cardiology guideline to make individualize drug dose [13]. 
In the present study, although the proportion of IM (53.07\%) was a higher frequency than EM (32.96\%). the results has no difference compared to other districts of China $(\mathrm{P}>0.05)$. The most important mutated allele was CYP2C19*2, which was predominantly responsible for PM and accounted for 96.0\% of the study population. The previous studies demonstrated that PM are more frequent (12-23\%) in the East Asian population, whereas the prevalence of PM were lower in West Asian, Scandinavians, South Americans, Europeans, and Africans [11,14-17]. In our study, the prevalence of the PM is $13.96 \%$, which consisted with that of other Asian populations.

In the study, we describe the genetic polymorphism of CYP2C19 in the CAD patients in Chongqing .The CYP2C19 allele and genotype frequencies were consisted with other populations. Our findings can provide an evidence for the early CR prediction, guide the rational drugs use, and reduce the ratio of adverse cardiovascular events in patients.

\section{Acknowledgements}

This work was supported by a grant from National Natural Science Foundation of China (No 81501818 of Yishu Tang) and the National Key Clinical Specialties Construction Program of China.

\section{Conflict of interest}

The authors declare no conflicts of interest.

\section{References}

1. Brandt JT, Close SL, Iturria SJ, Payne CD, Farid NA, Ernest CS, et al. Common polymorphisms of CYP2C19 and CYP2C9 affect the pharmacokinetic and pharmacodynamic response to clopidogrel but not prasugrel. J Thromb Haemost 5 (2007): 2429-2436.

2. Nguyen TA, Diodati IG, Pharan DC, et al. Resistance to clopidogrel:a review of the evidence. J Am Coil Cardiol 45 (2005): 1157-1164.

3. Xie HG, Zou JJ, Hu ZY, Zhang JJ, Ye F, et al. Individual variability in the disposition of and response to clopidogrel: pharmacogeno-mics and beyond. Pharmacol Ther 129 (2011): 267-289.

4. Hulot JS, Bura A, Villard E, Azizi M, Remones V, et al. Cytochrome P450 2C19 loss-of-function polymorphism is a major determinant of clopidogrel responsiveness in healthy subjects. Blood 108 (2006): 2244-2247.

5. Mega JL, Close SL, Wiviott SD, Shen L, Hockett RD, et al. Cytochrome p-450 polymorphisms and response to clopidogrel. N Engl J Med 360 (2009): 354-362.

6. Shuldiner AR, O’Connell JR, Bliden KP, Gandhi A, Ryan K, Horenstein RB, et al. Association of cytochrome P450 2C19 genotype with the antiplatelet effect and clinical efficacy of clopidogrel therapy. JAMA 302 (2009): 849-857.

7. Collet JP, Hulot JS, Pena A, Villard E, Esteve JB, Silvain J, et al. Cytochrome P450 2C19 polymorphism in young patients treated with clopidogrel after myocardial infarction: a cohort study. Lancet 373 (2009): 309-317.

8. Hulot JS, Collet JP, Silvain J, Pena A, Bellemain-Appaix A, Barthélémy O, et al. Cardiovascular risk in 
clopidogrel-treated patients according to cytochrome P450 2C19*2 loss-of-function allele or proton pump inhibitor coadministration: a systematic meta-analysis. J Am Coll Cardiol 56 (2010): 134-143.

9. Zou JJ, Xie HG, Chen SL, Tan J, Lin L, Zhao YY, et al. Influence of CYP2C19 loss-of-function variants on the antiplatelet effects and cardiovascular events in clopidogrel-treated Chinese patients undergoing percutaneous coronary intervention. Eur J Clin Pharmacol 69 (2013): 771-777.

10. Chang M, Dahl ML, Tybring G, Götharson E, Bertilsson L. Use of omeprazole as a probe drug for CYP2C19 phenotype in Swedish Caucasians: comparison with S-mephenytoin hydroxylation phenotype and CYP2C19 genotype. Pharmacogenetics 5 (1995): 358-363.

11. Persson I, Aklillu E, Rodrigues F, Bertilsson L, Ingelman-Sundberg M. S-mephenytoin hydroxylation phenotype and CYP2C19 genotype among Ethiopians. Pharmacogenetics 6 (1996): 521-526.

12. Chen BL, Zhang W, Li Q, Li YL, He YJ, Fan L, et al. Inhibition of ADP-induced platelet aggregation by clopidogrel is related to CYP2C19 genetic polymorphisms. Clin Exp Pharmacol Physiol 35 (2008): 904-908.

13. Wright RS, Anderson JL, Adams CD, Bridges CR, Casey DE Jr, Ettinger SM, et al. 2011 ACCF/AHA focused update of the Guidelines for the Management of Patients with Unstable Angina/Non-ST-Elevation Myocardial Infarction (updating the 2007 guideline): a report of the American College of Cardiology Foundation/American Heart Association Task Force on Practice Guidelines developed in collaboration with the American College of Emergency Physicians, Society for Cardiovascular Angiography and Interventions, and Society of Thoracic Surgeons. J Am Coll Cardiol 57 (2011): 1920-1959.

14. Masimirembwa C, Bertilsson L, Johansson I, et al. Phenotyping and genotyping of S-mephenytoin hydroxylase (cytochrome P450 2C19) in a Shona population of Zimbabwe. Clin Pharmacol Ther 57 (1995): 656-661.

15. Goldstein JA, Ishizaki T, Chiba K, et al. Frequencies of the defective CYP2C19 alleles responsible for the mephenytoin poor metabolizer phenotype in various Oriental, Caucasian, Saudi Arabian and American black populations. Pharmacogenetics 7 (1997): 59-64.

16. Herrlin K, Massele AY, Jande M, et al. Bantu Tanzanians have a decreased capacity to metabolize omeprazole and mephenytoin in relation to their CYP2C19 genotype. Clin Pharmacol Ther 64 (1998): 391-401.

17. Yamada S, Onda M, Kato S, et al. Genetic differences in CYP2C19 single nucleotide polymorphisms among four Asian populations. J Gastroenterol 36 (2001): 669-672.

Citation: Yishu Tang, Yang Yang, Ru Wu, Miao Gao, Fang Cui. Polymorphism of CYP2C19 gene polymorphism in Patients with Coronary Heart Disease in Chongqing. Archives of Clinical and Biomedical Research 2 (2018): 093-098.

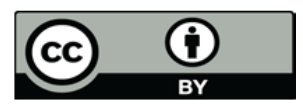

This article is an open access article distributed under the terms and conditions of the Creative Commons Attribution (CC-BY) license 4.0 